\title{
PERFORMANCE OF AN RCC FRAME BUILDING SUBJECTED TO HYDRODYNAMIC FORCE AT EACH FLOOR LEVEL - A CASE STUDY
}

\author{
Shreya H. Chokshi ${ }^{1}$, S.P.Dalal ${ }^{2}$ \\ ${ }^{1}$ Department of Civil Engineering, S.V.I.T. Vasad \\ ${ }^{2}$ Department of Civil Engineering, S.V.I.T. Vasad
}

\begin{abstract}
Buildings are essential in all populated cities. To increase value in certain buildings there are associated risks that we take like providing swimming pool at each floor level. Water carrying structures are more important that must remain functional following disasters such as earthquake. Most of the failures of structures after earthquakes are suspected to have resulted from the dynamic buckling caused by overturning moments of seismically induced liquid inertia and surface slosh waves. This paper investigates the hydrostatic and the hydrodynamic behavior of water in the swimming pool when subjected to earthquake forces. The main object of this paper is 1). To compare the static and dynamic analysis of the building. 2) The study of hydrodynamic effects.
\end{abstract}

Keywords: hydrostatic force, hydrodynamic, time history analysis, response spectrum method, displacement

$* * *$

\section{INTRODUCTION}

The trend of RCC high rise structures has increased nowadays in India. Many different amenities like swimming pool, garden etc. have been provided in high story building which is very attractive from an aesthetical point of view but it is dangerous from a structural point of view. Generally the buildings in India are being made using only static analysis, but when this type of high rise building with different amenities are made, dynamic check is also required. If the dynamic check is ignored then

Most of these buildings are likely to damage or collapse and may lead to very severe disaster. It may be very difficult to cope up with such a disaster.
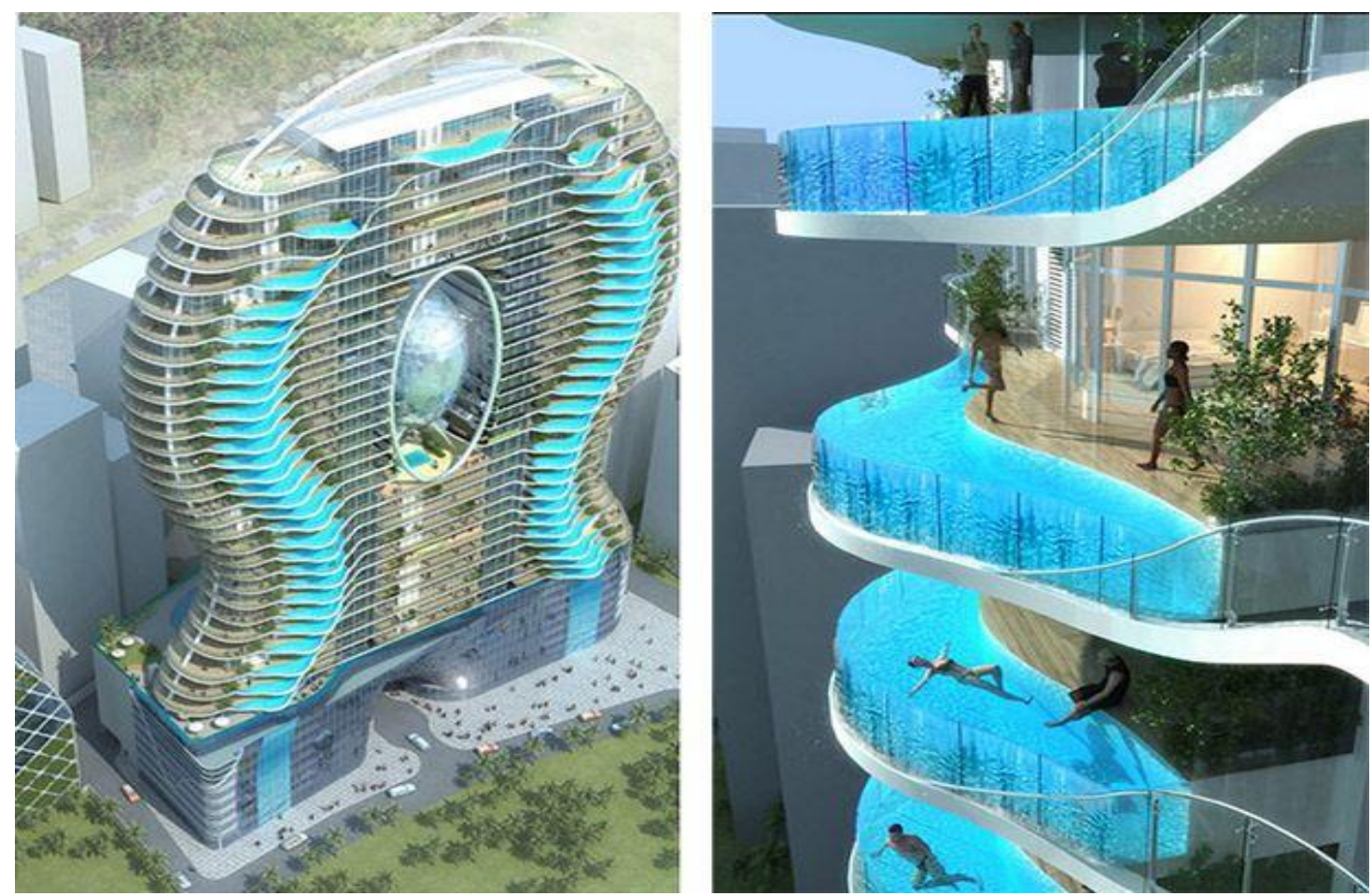

Fig. 1 The OHM residential steel building in Bandra 
Different amenity in an RCC frame in which one of them is an individual swimming pool at each floor. It is very important to select proper supporting systems and also need to study the response of RCC frame building subjected to hydrodynamic force at each floor level. It is also necessary to consider the sloshing effect on the wall and on the roof slab of the container. This sloshing of water considerably differs the parametric values used in design and economy of construction. The effect of hydrodynamic pressure on sides of the container as well as base slab of the container must be considered in the seismic analysis.

The study of earthquake damage provides valuable information about the performance of real structures during actual earthquake. The buildings designed and constructed by taking proper earthquake resistant measures have helped in minimizing the damage.

\section{LITERATURE REVIEW}

George W. Housner (1963) discussed the relation between the motion of the water with respect to the tank and the motion of the whole structure with respect to ground. He had considered three basic conditions, i.e. tank empty, tank partially filled and tank fully filled for the analysis and finally concluded that the maximum force to which the partiality fill tank subjected is less than the half the force to which the full tank is subjected. The actual forces may be little as $1 / 3$ of the forces anticipated on the basis of a completely full tank.

D.K Landge and Dr. Mrunal (2014) concluded that structural response is exceedingly influenced by different capacities of the water tank and their one mass and two mass models and earthquake characteristics. He has considered a reinforced elevated water tank with $1000 \mathrm{~m} 3,750 \mathrm{~m} 3,500 \mathrm{~m} 3$ capacities and supported by fixed base shaft type staging system . With considering one mass model as per IS:18931984 and two mass water model as per IS:1893-2002, seismic responses, including displacements and base shear were assessed under four earthquake records.

Chen and Kianoush (2004) discussed the procedure to determine hydrodynamic pressures for rectangular tanks. The method considers the effect of wall flexibility on impulsive pressures. The behavior of three types of open top tanks is studied under seismic ground motions. These tanks are classified as shallow, medium and tall tanks. Three suites of a time history, representing low, moderate and high earthquake zones are used for dynamic time history analysis. It is concluded that a lumped mass approach cannot realistically represent the true behavior of concrete liquid storage tanks.

Jain Sudhir k, Sameer (1990): The Indian code provisions for seismic design of elevated water tanks have been reviewed. The code must include an appropriate value of a performance factor, say 3.0 for calculation of seismic design force for water tanks. An earthquake design criteria are incomplete unless clear specifications are included on how to calculate time period. He also suggested that the code should also give more details of housner's mechanical analog model for hydrodynamic forces.

Sudhir K Jain and O. R. Jaiswal (2005) modified some of the previous provisions and some new provisions included. The major modifications are (1). Design horizontal seismic coefficient as given in IS 1893 (Part1): 2002 has been used for tanks and suitable values of importance factor I and response reduction factor $\mathrm{R}$ are proposed. (2) A Spring mass model which is common for tanks with rigid and flexible wall has been included (3) Some errors in the expression for convective hydrodynamic pressure are rectified (4) Sloshing wave height expression is simplified and (5) new provisions in effect of vertical ground acceleration, critical direction of seismic loading included.

O.R.Jaiswal and Sudhir K Jain (2005) suggested provisions of IS 1893:1984 on seismic design of liquid storage tanks have so far not been revised. In this paper detailed commentary describing the rational of modified provisions given in part 1 of this paper is provided with the help of examples. It clearly shows that for some ground supported tanks, design will be influenced by hydrodynamic forces. This clearly brings out the need for seismic analysis of ground supported tanks, which was not considered in IS 1893:1984. It is seen that provision of IS 1893:1984 can grossly underestimate design forces for certain elevated tanks.

V.S.Bachal (2006) concluded that the conventional method of analyzing the problem of water tank as a single degree of freedom system, gives the conservative results when compared with those obtained by considering the same problem of water tank as a two degree of freedom system , thus by making its design heavy and costly. This confirms the need to adopt this new approach of analyzing and designing the water tank by considering it as a two degree of freedom system to make its design economical and safe against additional hydrodynamic pressure due to sloshing of water.

Gaikwad Madhukar V. , Mangulkumar Madhuri N. (2013) concluded that for the same capacity, same geometry, same height, with the same staging system, in the same zone, with same Importance Factor \&response reduction factor ; response by Equivalent Static Method to Dynamic method differ considerably.

\section{DISCUSSION}

The dynamic behavior of an elevated tank may be quite different in certain proportions of the tank and the structure. The sloshing may have a small effect, therefore an understanding of the earthquake damage, or survival of elevated water tanks requires an understanding of the dynamic forces associated with the sloshing water. (George W. Housner, (1963))

The sloshing events can affect the overall performance of the parent structure. ( Koli, and .Kulkarni (2010)). 
If the hydrodynamic factors are ignored during the analysis they will affect vigorously and collapse of the structure can take place. (Gaikwad Madhukar V., Mangulkumar Madhuri N (2013)

\section{PROBLEM FORMULATION}

The present study is a case study of AVALON building . This building is a residential building with individual swimming pool at each floor level. Actually it is against the principle of earthquake resistant design, as a huge mass is concentrated at each floor level. The impact of this phenomenon, many architects fail to understand or refuse to understand and they plan their building to the demands of the client.

So the burden and responsibility of safe design of such structure are left to the helpless structural engineer, who has little voice in such options. So for safety purpose, it is required to consider static as well as dynamic analysis of the building.

Table-1 The dimensions and the structural details of the frame are as follows

\begin{tabular}{|l|l|}
\hline Type of structure & $\begin{array}{l}\text { Multistory rigid jointed } \\
\text { 3D frame (OMRF) }\end{array}$ \\
\hline Seismic zone & 3 \\
\hline Zone factor & 0.16 \\
\hline Importance factor & 1.0 \\
\hline Type of soil & Medium soil \\
\hline Dimension of building & $26 \mathrm{~m} \times 30 \mathrm{~m}$ \\
\hline
\end{tabular}

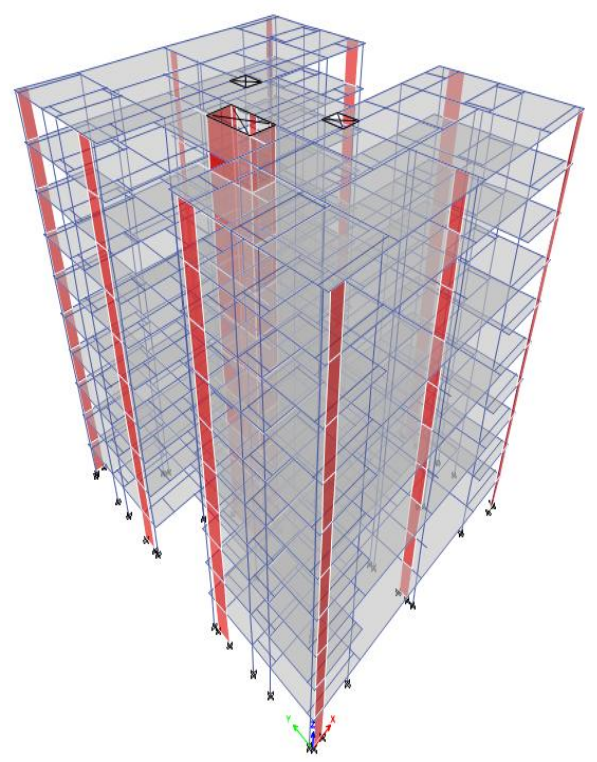

Elevation of Frame

\begin{tabular}{|l|l|}
\hline Floor height & $3 \mathrm{~m}$ \\
\hline Depth of slab & $125 \mathrm{~mm}$ \\
\hline Density of concrete & $25 \mathrm{~N} / \mathrm{mm}^{2}$ \\
\hline Density of brick masonry & $20 \mathrm{~N} / \mathrm{mm}^{2}$ \\
\hline Grade of structural steel $\left(\mathrm{f}_{\mathrm{y}}\right)$ & $\mathrm{Fe} 415$ \\
\hline Grade of concrete $\left(\mathrm{f}_{\mathrm{ck}}\right)$ & $\mathrm{M} 25$ \\
\hline Density of water & $9.81 \mathrm{kN} / \mathrm{m}^{3}$ \\
\hline
\end{tabular}

Table-2 Details of loading

\begin{tabular}{|l|l|}
\hline DETAILS OF LOADING \\
\hline Floor finish & IS:875 (PART 2) -1987 \\
\hline 1) Roof & $2 \mathrm{kN} / \mathrm{m}^{2}$ \\
\hline 2) All the room, kitchen, etc. & $1 \mathrm{kN} / \mathrm{m}^{2}$ \\
\hline Live load & IS:875 (PART 2)-1987 \\
\hline 1) All rooms \& kitchen & $2 \mathrm{kN} / \mathrm{m}^{2}$ \\
\hline 2) Toilet and bathrooms & $2 \mathrm{kN} / \mathrm{m}^{2}$ \\
\hline 3) Corridors, passages & $2 \mathrm{kN} / \mathrm{m}^{2}$ \\
\hline 4) Balconies & $3 \mathrm{kN} / \mathrm{m}^{2}$ \\
\hline 5) Roof & $2 \mathrm{kN} / \mathrm{m}^{2}$ \\
\hline Lateral load is considered as per IS $1893: 2002$ \\
\hline
\end{tabular}

\section{MODELLING OF THE FRAME}

The study frame is modeled in ETABS 2013 after applying the dead loads and live loads as per IS 875-1987 (II). The slabs of floors as well as that of swimming pools were modeled as rigid diaphragms. The size of swimming pool is $7.9 \mathrm{~m} \times 5.0673 \mathrm{~m} \times 1.2 \mathrm{~m}$. If the pool is full, then it can carry water up to 47997.24 liters. Hence, this pool is designed for 48000 liters capacity.

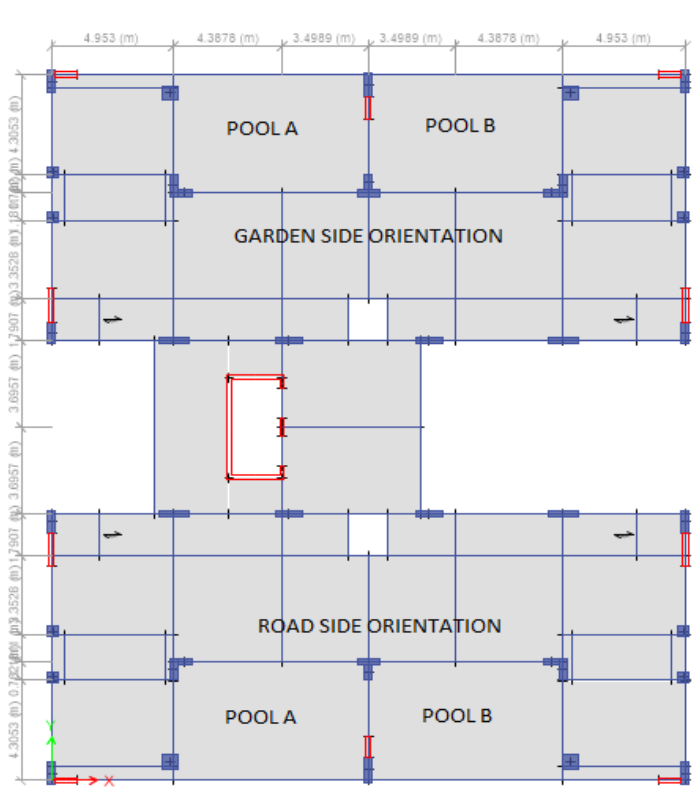

Plan of Frame 


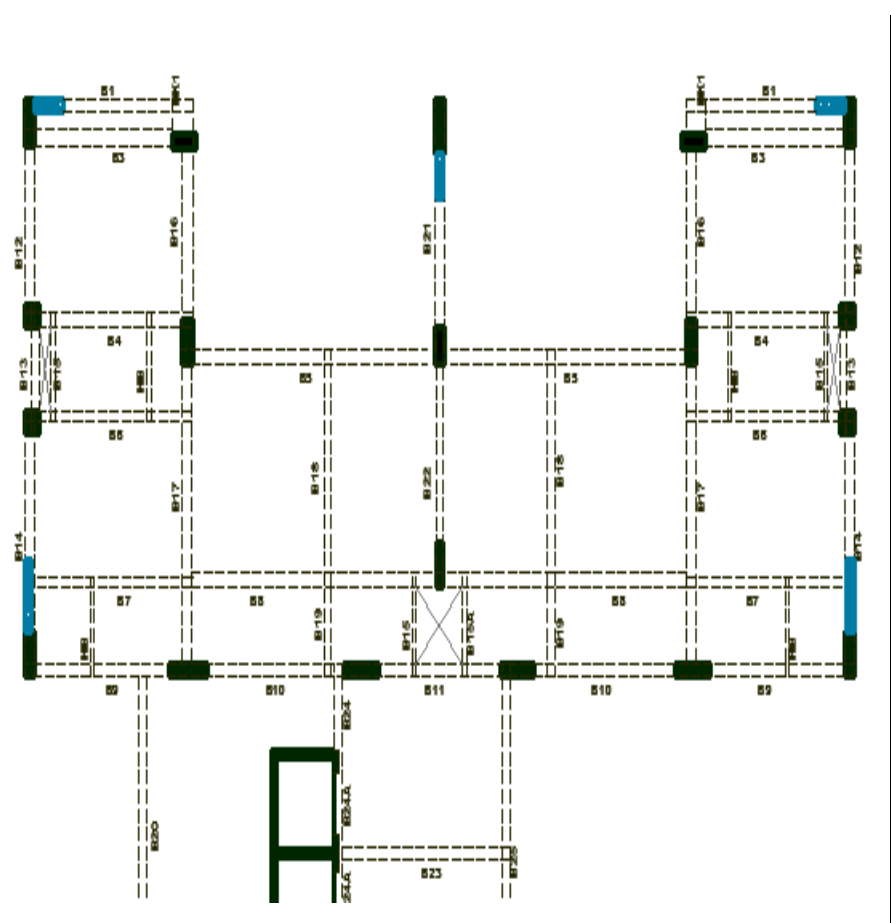

Numbering of Beam of Ground Floor

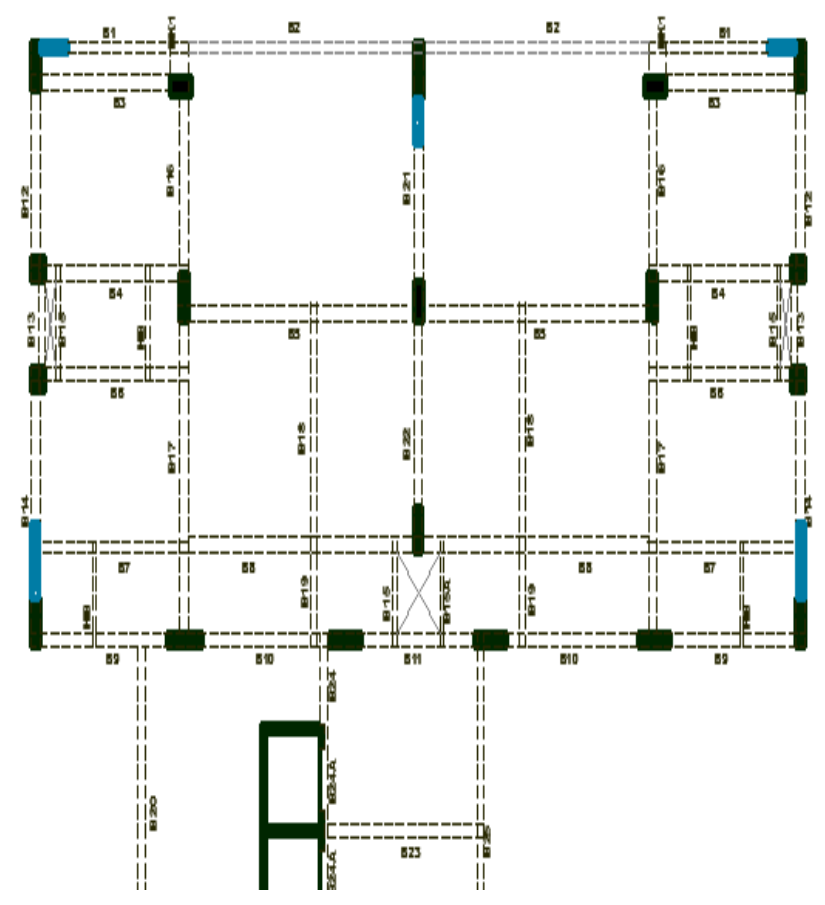

Numbering of Beam of First Floor

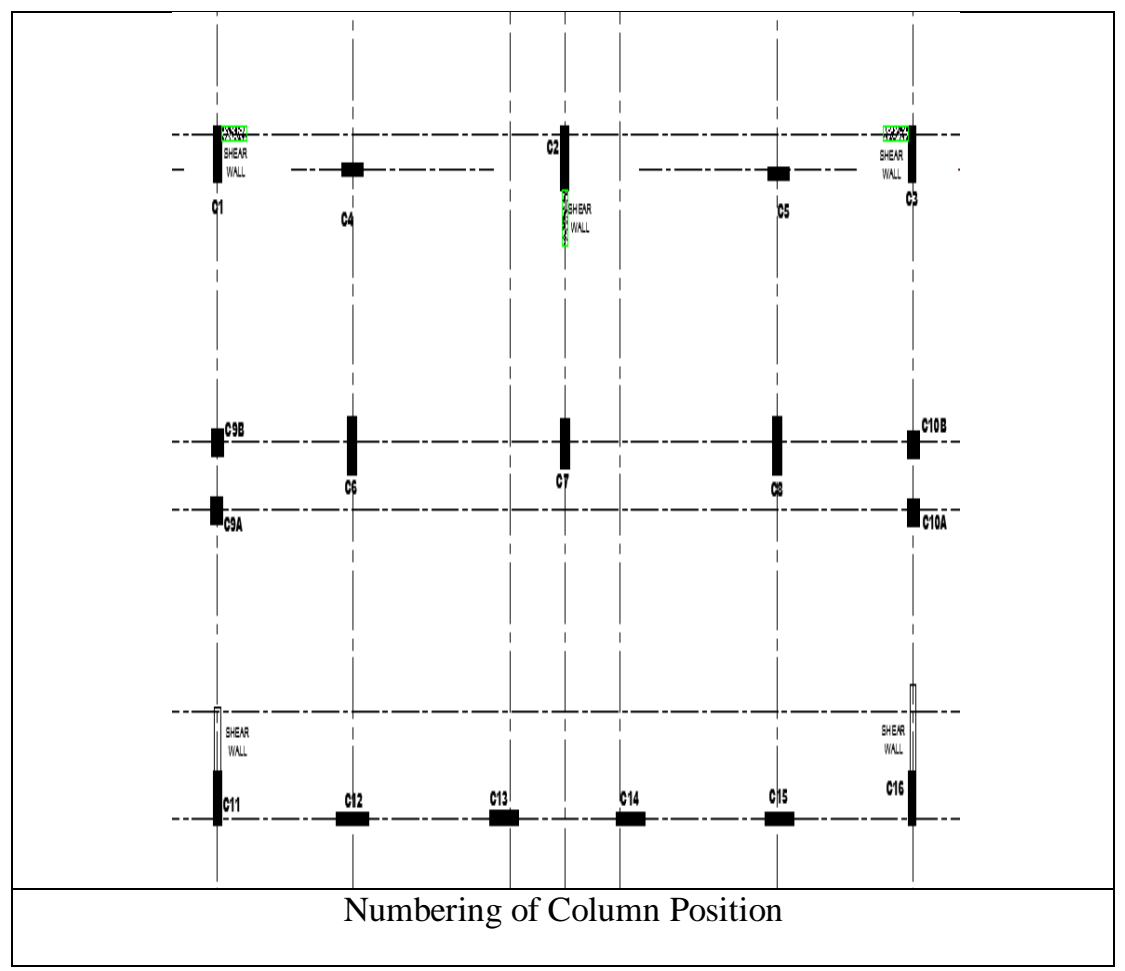

\section{PERFORMANCE OF A RCC FRAME UNDER RESPONSE SPECTRUM METHOD}

Response spectrum analysis is used in earthquake engineering, which describes the maximum response of a SDOF system to a particular input motion (i.e. the respective accelerogram) .Response spectrum method dependent on damping ratio $\xi(1-10 \%)$. It reflects the maximum response to simple structures (SDOF). A response spectrum is simply a plot of the peak or steady-state response (displacement, velocity or acceleration) of a series of oscillators of varying natural frequency, that are forced into motion by the same base vibration or shock. The resulting plot can then be used to pick off the response of any linear system, given its 
natural frequency of oscillation. One such use is in assessing the peak response of buildings to earthquakes. The science of strong ground motion may use some values from the ground response spectrum (calculated from recordings of surface ground motion from seismographs) for correlation with seismic damage.

The selected RCC OMRF study frame was analyzed for static loads as well as a response spectrum method (as per IS1893:2002) with the help of ETAB2013 software and found safe. The design has been carried out based on the obtained analysis results satisfying the IS 456:2000 codal provisions. The swimming pool is designed as a water tank resting on the ground as per IS 3370 (part П) and IS 3370 (part IV).

Again the behavior of this designed frame when subjected to variable hydrostatic force at each floor level will be unpredictable and totally different when subjected to hydrodynamic force.

The hydrodynamic force is variable in the sense that the swimming pools of different residences may be empty or full especially during maintenance (cleaning).

These conditions need to be checked.

\begin{tabular}{|l|l|l|l|l|l|l|}
\hline \multicolumn{5}{|c|}{ Table 3- The conditions to be observe the critical response of the structure } \\
\hline SR NO. & FLOOR & \multicolumn{2}{|l|}{ ROAD SIDE ORIENTATION } & \multicolumn{2}{l|}{ GARDEN } \\
NORIENTATION
\end{tabular}




\begin{tabular}{|c|c|c|c|c|c|c|}
\hline & 9 & EMPTY & EMPTY & EMPTY & EMPTY & \multirow{6}{*}{$\begin{array}{l}\text { TWO } \\
\text { MEMBERS } \\
\text { FAIL }\end{array}$} \\
\hline & 1 & FULL & FULL & EMPTY & EMPTY & \\
\hline & 3 & FULL & FULL & EMPTY & EMPTY & \\
\hline & 5 & FULL & FULL & EMPTY & EMPTY & \\
\hline & 7 & FULL & FULL & EMPTY & EMPTY & \\
\hline 8 & 9 & FULL & FULL & EMPTY & EMPTY & \\
\hline \multirow{5}{*}{9} & 1 & FULL & FULL & FULL & FULL & \multirow{5}{*}{ NO FAILURE } \\
\hline & 3 & EMPTY & EMPTY & EMPTY & EMPTY & \\
\hline & 5 & EMPTY & EMPTY & EMPTY & EMPTY & \\
\hline & 7 & EMPTY & EMPTY & EMPTY & EMPTY & \\
\hline & 9 & EMPTY & EMPTY & EMPTY & EMPTY & \\
\hline \multirow{5}{*}{10} & 1 & FULL & FULL & FULL & FULL & \multirow{5}{*}{ NO FAILURE } \\
\hline & 3 & EMPTY & EMPTY & EMPTY & EMPTY & \\
\hline & 5 & EMPTY & EMPTY & EMPTY & EMPTY & \\
\hline & 7 & EMPTY & EMPTY & EMPTY & EMPTY & \\
\hline & 9 & FULL & FULL & FULL & FULL & \\
\hline \multirow{5}{*}{11} & 1 & FULL & FULL & FULL & FULL & \multirow{5}{*}{ NO FAILURE } \\
\hline & 3 & FULL & FULL & FULL & FULL & \\
\hline & 5 & EMPTY & EMPTY & EMPTY & EMPTY & \\
\hline & 7 & FULL & FULL & FULL & FULL & \\
\hline & 9 & FULL & FULL & FULL & FULL & \\
\hline \multirow{5}{*}{12} & 1 & FULL & FULL & EMPTY & EMPTY & \multirow{5}{*}{ NO FAILURE } \\
\hline & 3 & EMPTY & EMPTY & FULL & FULL & \\
\hline & 5 & FULL & FULL & EMPTY & EMPTY & \\
\hline & 7 & EMPTY & EMPTY & FULL & FULL & \\
\hline & 9 & FULL & FULL & EMPTY & EMPTY & \\
\hline \multirow{5}{*}{13} & 1 & EMPTY & EMPTY & EMPTY & EMPTY & \multirow{5}{*}{ NO FAILURE } \\
\hline & 3 & EMPTY & EMPTY & EMPTY & EMPTY & \\
\hline & 5 & EMPTY & EMPTY & EMPTY & EMPTY & \\
\hline & 7 & EMPTY & EMPTY & EMPTY & EMPTY & \\
\hline & 9 & FULL & FULL & FULL & FULL & \\
\hline
\end{tabular}

Maximum story displacement X-Direction

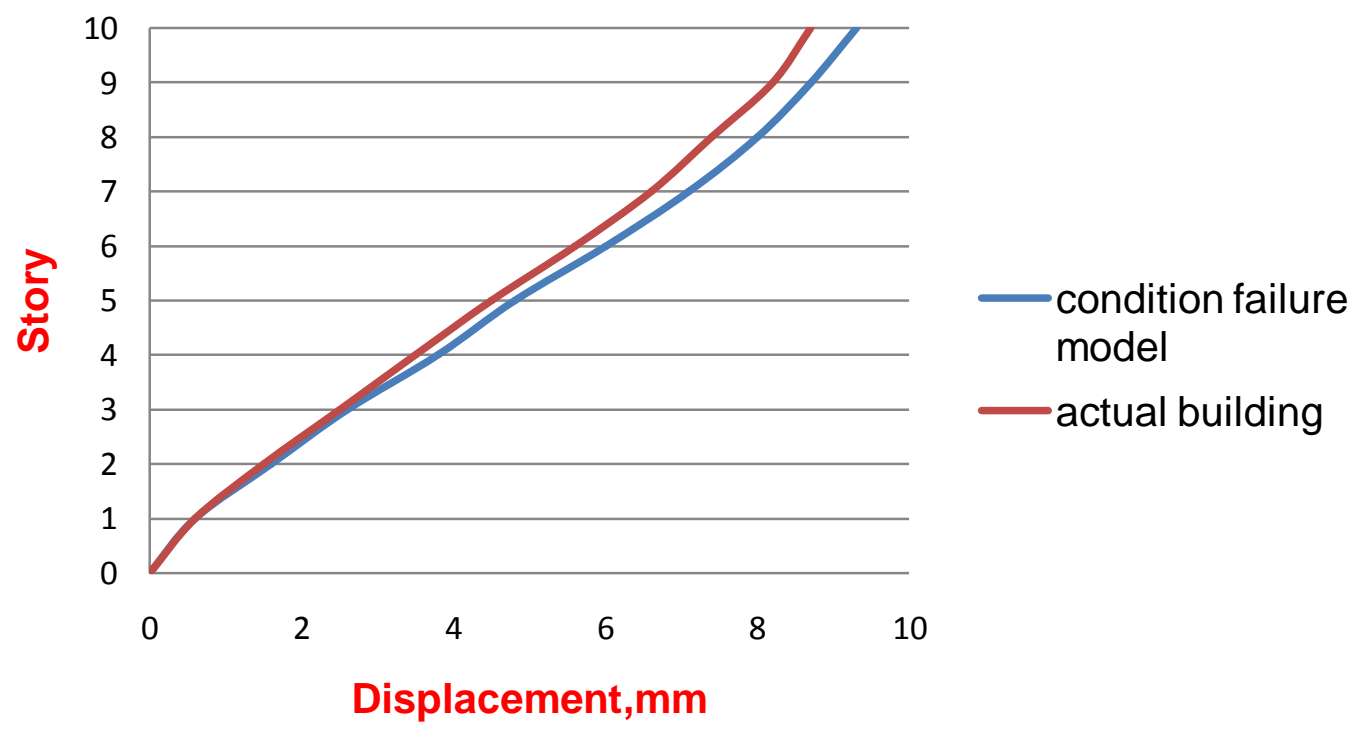

Fig 2: maximum story displacement in $\mathrm{X}$ - direction 
- When earthquake considered in $X$-direction, the displacement of roof of the actual building is $8.7 \mathrm{~mm}$ while the displacement of the condition failure model is $9.3 \mathrm{~mm}$.

\section{OBSERVATIONS}

The Avalon building fails in pool condition number 4 and 8 while checking by response spectrum analysis. Henceforth, the residents shall be instructed that, "All the residents of one side tower should not empty and other side residents of other side tower should not fill the swimming pool at the same time."

\section{PERFORMANCE OF A RCC FRAME UNDER TIME HISTORY ANALYSIS}

The time - history analysis provides for linear or nonlinear evaluation of dynamic structural response under loading which may vary according to the specified time function.
The advantage of these linear dynamic procedures with respect to linear static procedures is that higher modes can be considered. In time history analyses the structural response is computed at a number of subsequent time instants. In other words, time histories of the structural response to a given input are obtained as a result. In response spectrum analyses the time evolution of response cannot be computed. Only the maximum response is estimated.

Selection of earthquake records for dynamic analysis The time history of ground motions adopted in this study is carried out. Two sets f time history in locations of Bhuj as well as RINALDI are taken in Seismic zone 3 are used for dynamic analysis. Detailed information of these earthquake records is listed in Table 4.1 An integration time step of 0.005 seconds is used to guarantee the accuracy of sequential analysis.

Table 4: Detailed information of two suites of Time History Ground Motion

\begin{tabular}{|l|l|l|l|l|l|}
\hline $\begin{array}{l}\text { NEAR FAULT EARTHQUAKE } \\
\text { GROUND MOTION }\end{array}$ & $\begin{array}{l}\text { RECORDING } \\
\text { STATION }\end{array}$ & $\begin{array}{l}\text { DURATION } \\
\text { ( Sec) }\end{array}$ & $\begin{array}{l}\text { PGD } \\
\text { m }\end{array}$ & $\begin{array}{l}\text { PGV } \\
\text { (m/sec) }\end{array}$ & $\begin{array}{l}\text { PGA } \\
(\mathbf{g})\end{array}$ \\
\hline January 26, 2001, Bhuj, Gujarat & Ahmedabad & $\begin{array}{l}46.940 \\
(26706 / 0.05)\end{array}$ & 0.088 & 0.11 & 0.11 \\
\hline $\begin{array}{l}\text { January 17, 1994 Northridge, } \\
\text { California }\end{array}$ & Rinaldi & $\begin{array}{l}14.950 \\
(2990 / 0.005)\end{array}$ & 0.391 & 1.75 & 0.89 \\
\hline
\end{tabular}

1) The performance of the study frame was checked for the difference between response spectrum analysis and time history analysis.

\section{( a ) BHUJ}

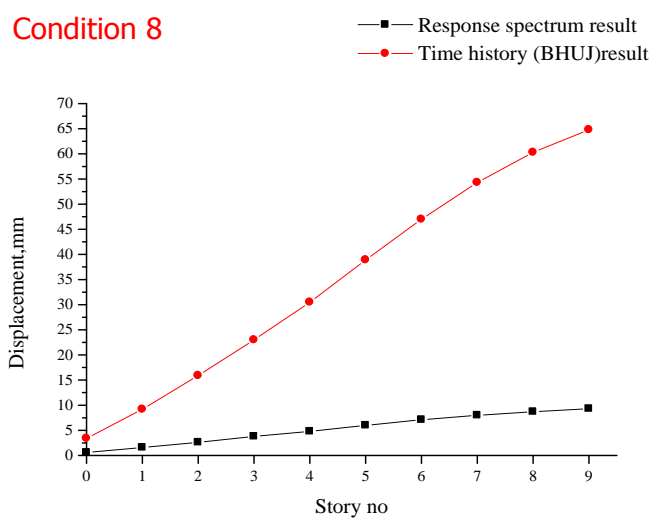

\section{COMMENTS}

$>\quad$ The graph shows the condition 8 analyzed by both ground motion.

$>$ There is a wide difference between the displacement of the frame under response spectrum method and time history method. The frame undergoes large displacement when subjected to ground excitation especially in condition 8 .

\section{( b ) RINALDI}

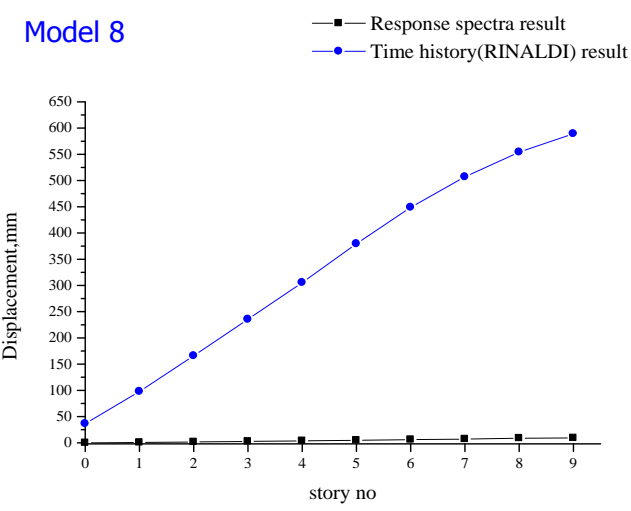

This study is a case study of existing RCC frame situated at sevasi which gives swimming pool at each flat as an amenity. The selected study frame was designed as per the current structure method in which lateral load is calculated using the response spectrum method as per IS 1893-2002, and the design is done as per IS 456-2000. The design frame was checked under two ground motion, namely BHUJ earthquake and RINALDI earthquake for various conditions of swimming pool. 


\section{CONCLUSION}

Following conclusions are made as follows:

$>$ Avoid construction of heavy structures like garden, swimming pool, water tank, etc. at upper floor levels.

$>$ If the amenities like swimming pool, garden etc. are provided, then the dynamic response of the building should be carried out.

> Residents shall be instructed about the most critical conditions of empty or full water level at different floors.

$>$ This type of structure in a non seismic zone is safe in case of earthquakes with the lower ground motion of less time, but it is not safer in higher seismic zone areas.

\section{REFERENCES}

[1]. George W. Housner, (1963) "The Dynamic Behavior of Water Tank" Bulletin of the Seismological Society of America. Vol. 53, No. 2,pp. 381-387.

[2]. Sudhir K. Jain, Sameer U.S.,(1990), "Seismic Design of Frame Staging For Elevated Water Tank" Ninth Symposium on Earthquake Engineering (9SEE-90), Roorkey, December 14-16, Vol-1.

[3].Jaiswal O. R and Sudhir K Jain(2005), "Modified proposed provisions for seismic design of liquid storage tanks: Part I - codal provisions", Journal of Structural Engineering Vol. 32, No.3, August- September pp 195-206 [4]. Jaiswal O. R and Sudhir K Jain(2005), "Modified proposed provisions for seismic design of liquid storage tanks: Part II - commentary and examples", Journal of Structural Engineering Vol. 32, No.4, October-November 2005

[5]. IITK-GSDMA guidelines for seismic design of liquid storage tanks.

[6]. IS 1893-2002 criteria for earthquake resistant design of structures.

[7]. V.S.Bachal (2006) "Effects of sloshing on analysis and design of service reservoirs" International Journal of Engineering Science and Technology (IJEST)

[8]. Mr. G.C. Koli, Prof. V. Kalilkarni(2010). "Simulation of Fluid Sloshing in a Tank" World Congress on Engineering, Vol II, June 30 - July 2, London, U.K.

[9]. Mangulkar Madhuri. N. And Gaikwad Madhukar V. (2013), "Review on Seismic Analysis of Elevated Water Tank", International Journal of Civil Engineering \& Technology (IJCIET), Volume 4, Issue 2, 2013, pp. 288 294, ISSN Print: 0976 - 6308, ISSN Online: 0976-6316.

[10]. Chen And kianoush (2004) "response of concrete liquid containing structures in different seismic zones" 13th World Conference on Earthquake Engineering, Vancouver, B.C., Canada August 1-6, 2004 Paper No. 1441 [11]. Landge and Mrunal (2014) "Structural Assessment of Circular Overhead Water Tank Based on Shaft Staging Subjected to Seismic Loading "International Journal of Emerging Technology and Advanced Engineering Volume 4, Issue 6, June 2014.

[12]. IS 456-200 plain and RCC code of practice. 